\title{
A comparative study on the embryo-fetal development in rabbits after artificial insemination
}

\author{
Kosisochukwu Kingsley Obasi, Ezra Lambe, Ismail Temitayo Gbadamosi, Adeoye Oyetunji Oyewopo \\ Department of Anatomy, Faculty of Basic Medical Sciences, University of Ilorin, Ilorin, Kwara State, Nigeria
}

\begin{abstract}
Objectives: Artificial insemination (AI) is the introduction of spermatozoa into a female's uterus or cervix for the purpose of achieving pregnancy. It is a fertility treatment for humans, in animal breeding and embryo-fetal developmental studies. This study investigated the embryo-fetal development in the rabbit via artificial insemination by evaluating the litter size, reproductive data and external morphological abnormalities after insemination.

Methods: Ten adult female and three male rabbits weighing $1.8 \mathrm{~kg}$ and $2 \mathrm{~kg}$, respectively were used. Group A served as the natural mating, while Group B served as the Al group, and the males served as semen donors. On day 28 of gestation, does were subjected to caesarean section. The ovaries and uteri were removed and examined for the number of corpora lutea and the status of all implantation.

Results: Results showed a significant increase in fetal weight, total fetal number, total resorption sites, number of implantation and total number of live foetuses $(p<0.05)$, while there was no significant increase in parameters like average fetal weight, placenta weight, uterine gravid weight, number of corpora lutea and sex ratio in Group B compared to Group A ( $p>0.05$ ). A conception rate of $100 \%$ was observed in Group A compared to Group B with $80 \%$ conception rate. External examination carried out on the foetuses revealed no external abnormalities in both groups.
\end{abstract}

Conclusion: The results of this study show the clear advantages in the use of rabbits for Al in terms of embryo-fetal developmental studies.

Keywords: artificial insemination; caesarean section; embryo-fetal development

Anatomy 2016;10(2):105-113 @2016 Turkish Society of Anatomy and Clinical Anatomy (TSACA)

\section{Introduction}

Artificial insemination (AI) can be defined as the deliberate action of introducing sperm into the female's reproductive tract (uterus or cervix) to achieve pregnancy by means other than sexual intercourse for infertility treatment in humans and also for animal breeding. The increase in density of gametes at the fertilization sites during artificial insemination has been the rationale behind the process. The improvement in selection differential was accomplished by mating thousands of females with a highly virile male, thereby maintaining the flow of genes through different generations. ${ }^{[1]}$ Genetic improvement rate in farm animals helped to increase animal productivity thereby seeking the further adoption of this technique. ${ }^{[2]}$ The significance of this technique includes pro- longing fertility during harsh times of the year, better breeding programs, favorable gene selection, health monitoring improvements and finally cycle-based production. ${ }^{[3]}$ In Nigeria different methods of controlled mating has played a minor role thereby, bringing a slow development of AI in the country. Few reports of AI have been documented in different animals, e.g. in cattle, ${ }^{[4]}$ sheep,${ }^{[5]}$ pigs, ${ }^{[6]}$ turkeys,${ }^{[7]}$ and poultry animals. ${ }^{[8]}$ The use of rabbit AI has become a common practice in the world, leading to changes in operation of farm management, life style improvement of farmers and finally an increase in farm productivity. Administration of exogenous substances such as the use of gonadotrophin releasing hormone $(\mathrm{GnRH})$ to induce ovulation is needed during the process of $\mathrm{AI} .{ }^{[9]}$ Ovulation in the rabbit does not occur sponta- 
neously but through a neurohormonal reflex initiated during coitus. Ovulation can be induced artificially in the absence of a buck, and the most frequently used ovulation inductor is the use of a synthetic analogue or intramuscular injection of GnRH. Hormonal substances like human chorionic gonadotrophin (HCG) and luteinizing hormone (LH) could serve as ovulation inductors in does alternatively. However, failure to induce ovulation could occur as a result of antibody formation due to repeated injection of these hormonal substances. ${ }^{[9]} \mathrm{AI}$ in rabbits is usually done with fresh semen, yielding pregnancy rates similar with natural mating. ${ }^{[10]}$ In recent years, extensive studies have been carried out to determine the effect of natural and artificial mating on reproductive traits between two breeds of rabbits, semen parameters, effects of hormonal treatments on artificial mating, etc. Therefore, this study aims to evaluate the possible embryo-fetal developmental studies in rabbits artificially inseminated with semen from the cauda epididymis compared to those mated naturally proffering solutions and provide insights into various aspects of reproductive health.

\section{Materials and Methods}

Ten (10) nulliparous adult female New Zealand White, California White and Chinchilla rabbits with an average weight of $1.8 \mathrm{~kg}$ and three adult male New Zealand white rabbits purchased from Ladoke Akintola University of Technology, Ogbomosho, Oyo State were used. Animals were put in separate cages ( 2 does per cage while the bucks were housed separately) and housed at the Department of Agriculture Rabbtry, University of Ilorin, at normal room temperature and maintained under 12 hours light/12 hours dark cycle. They were fed pelletized growers feed from Ogo Oluwa Feed Mills Limited, Ilorin, Kwara State containing $15 \%$ crude protein, $7 \%$ fat, $10 \%$ crude fibers, $1 \%$ calcium, $0.35 \%$ phosphorus, Tridax plant and Potato leaves as supplements. Clean drinking water was provided and a hygienic environment ensured.

The animals were grouped into two: Group A served as the natural mating group consisted of a buck and 5 does. Group B served as the artificial insemination group, consisting of 2 bucks and 5 does. Semen preparation for Group B was from cauda epididymis of the bucks in that group. Bucks in Group B served as semen donors while the does served as semen recipients.

The receptivity of does was evaluated by the color of the vulva method. Vulva was examined to determine the presence of red or pink coloration just before the artificial insemination which indicated a receptive rabbit. A purple or white colouration indicated a non-receptive rabbit.
The bucks were anaesthetized with ketamine injection and an abdominopelvic incision was made on the left scrotum exposing the reproductive organs of the bucks. The testes, cauda epididymis and some part of the vas deferens were removed and later discarded after use. The bucks were sutured back after incision and lidocaine powder was applied to the sutured area to prevent spread of infection and aid healing respectively.

The semen was collected from the testes, cauda epididymis and some part of the vas deferens, and the bucks were sutured back after incision. The left epididymis was dissected in $10 \mathrm{ml}$ of normal saline maintained at a temperature of $38^{\circ} \mathrm{C}$, while semen was retrieved from the vas deferens via flushing with normal saline. $1-1.5 \mathrm{ml}$ of the sperm suspension was diluted to a total of $20 \mathrm{ml}$ with sterile normal saline at a temperature of $38^{\circ} \mathrm{C}$.

Macroscopic parameters included examination of semen colour, smell and analysis of sperm $\mathrm{pH}$. A normal sperm sample has a homogeneous white opalescent appearance. Dark, yellow or other abnormal semen samples were discarded.

Microscopic parameters like sperm concentration, motility, live/death ratio were measured. Sperm concentration was determined using a haemacytometer (Neubauer chamber). This method is commonly employed to determine the sperm concentration in rabbit semen at the beginning of AI procedure. ${ }^{[1]}$

The semen used in the artificial insemination was collected from the bucks and was considered having satisfactory quality. At the day of insemination (1st day of $\mathrm{AI}$ ), the color of vulva was examined and for the does that were accepted as receptive, AI was performed. AI was performed using an angled catheter connected to $2 \mathrm{ml}$ inseminating syringe with a bent shaft at the end ${ }^{[12]}$ as shown in Figure 1a. Prior to insemination, the animals were held in a supine position (Figure 1b) after it was discovered that this position was more convenient as described by Mroueh and Mastroianni. ${ }^{[13]}$ A dose of AI contained an average of 5 $6 \times 10^{6}$ million spermatozoa and each doe received $0.5 \mathrm{ml}$ of the semen suspension into their vagina. Immediately after artificial insemination, each doe received $0.1 \mathrm{ml} / 10$ IU of HCG intravenously to induce ovulation via the marginal ear vein. ${ }^{[9]}$ The day of insemination was accepted as Day 0 of gestation. Fourteen days after artificial insemination, pregnancy diagnosis was performed by hand palpation.

It should be noted that the time taken to complete semen collection from the cauda epididymis to the termination of artificial insemination in the does was completed in less than 45 minutes. Therefore, the condition of the animals, period of artificial insemination and time taken 
could be arbitrarily controlled in contrast with semen collection using an artificial vagina which takes an average of 1-2 hours as reported by Kim et al. ${ }^{[14]}$

On day 28 of gestation, the dams were anaesthetized with ketamine and subjected to caesarean section. The ovaries and uterus were examined for the following: implantation sites, total number of resorption sites, uterine gravid, weight of foetuses, sex ratio, total number of foetuses and placental weights. Live foetuses were examined for external morphological abnormalities. External morphological findings are classified as developmental malformations and have been used by researchers in an internationally developed glossary for structural developmental abnormalities in laboratory mammals. ${ }^{[15]}$ Implantation sites were viewed by the application of a drop of ammonium sulphide $\left(\mathrm{NH}_{4}\right)_{2} \mathrm{~S}$ solution on the animal's placenta and left for a day to view dark implantation rings signifying the number of implantation sites. The ovaries were excised and fixed in Bouin's fluid for corpora lutea count. The excised ovaries were placed inside a tissue cassette and then subjected to the manual routine tissue processing procedure as explained below. Ovarian tissues were subjected to the processes of fixation, dehydration, clearing, infiltration, embedding, sectioning, staining, mounting and examination on glass slides as described by Drury and Wallington. ${ }^{[16]}$ The tissues were trimmed down to sizes of $3 \mu \mathrm{m}$ thick using a microtome.

The experimental protocol was approved by the University ethical review committee, University of Ilorin, Ilorin, Nigeria. The research was in compliance with the University of Ilorin Animal Care and Use committee (UIACUC).

Data from both groups were statistically analysed using Student's t-test followed by subsequent analysis by GraphPad Prism version 5.01 for Windows (GraphPad Software, San Diego, CA, USA) with statistical significance set at $\mathrm{p}<0.05$.

\section{Results}

\section{Changes in body weight}

The body weight of animals in Group A and B were on a continuous rise over the period of confirmed pregnancy, but a significant increase $(\mathrm{p}<0.05)$ in their body weight at day 7, day 14, day 21 and day 28 of pregnancy was observed in Group B compared to Group A (Figure 2).

\section{Reproductive data}

Reproductive data from Group A and Group B are shown in Table 1. A 100\% conception was observed in Group A, while in Group B a 80\% conception rate was recorded.
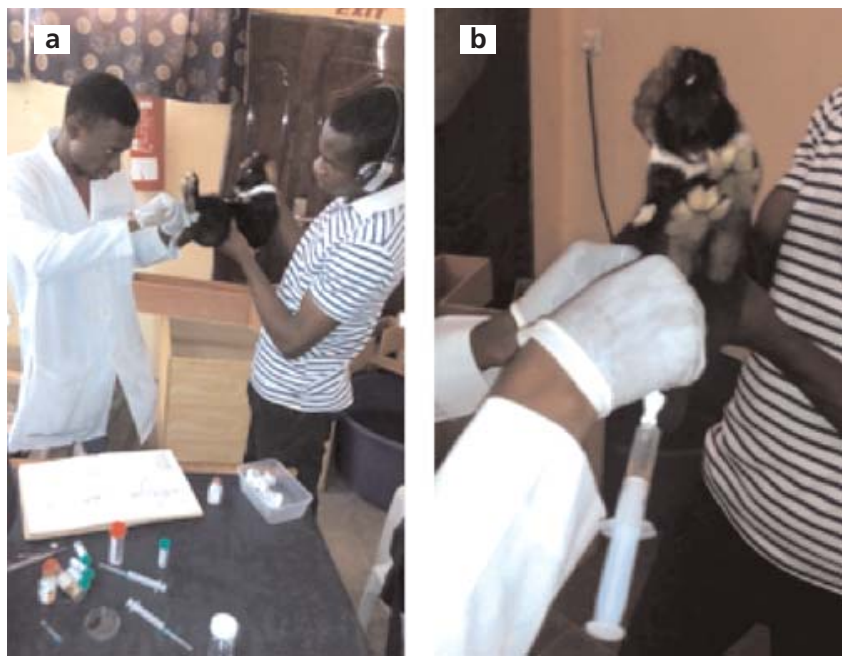

Figure 1. $(\mathbf{a}, \mathbf{b})$ The process of artificial insemination. [Color figure can be viewed in the online issue, which is available at www.anatomy.org.tr]

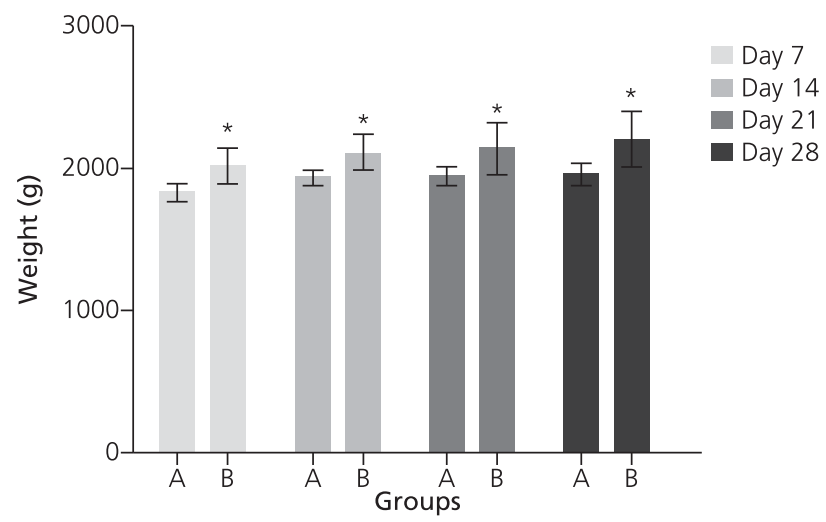

Figure 2. Changes in body weight on day 7, 14, 21 and 28 of gestation for Group A and Group B. ${ }^{*} p<0.05$

Table 1

Reproductive data of does in Group A and Group B.

\begin{tabular}{lcc}
\hline Parameters & Group A & Group B \\
\hline Number of does & 5 & 5 \\
Number of implantation & 5 & 5 \\
Conception rate & 100 & 80 \\
Number of dead does & - & - \\
Number of aborted does & - & 1 \\
Number of does with live fetuses & $5(100 \%)$ & $4(80 \%)$ \\
\hline
\end{tabular}

Abortion was observed in one doe on day 21 of gestation in Group B, while none was observed in Group A. Thus, the reproductive data showed better results in Group A compared to Group B. 


\section{Caesarean section data}

Following caesarean section, more male and female rabbits were recorded in Group B compared to Group A (Table 2). The number of foetuses examined in Group B (34) was slightly higher compared to Group A (28). The total number of resorption increased significantly $(\mathrm{p}<0.05)$ in Group B (8) compared to Group A which recorded a low resorption number (2). No external abnormalities were recorded in both groups.

\section{Embryo-fetal developmental studies}

Following caesarean section, embryo-fetal developmental studies carried out for Group A and Group B showed that a significant increase in parameters like total number of fetuses (Figure 3), number of implantations and total number of live foetuses and total resorption sites in Group B compared to Group A ( $<<0.05)$. There was no significant increase in parameters like average fetal weight $(\mathrm{g})$, placenta weight (g), uterine gravid (g) (i.e. total fetal weight in the uterus), number of corpora lutea (CL), sex ratio $(\mathrm{M} / \mathrm{F})$ in Group B compared to Group A ( $>0.05)$ (Figures 4-9).

\section{Discussion Changes in body weight}

Body weight of animals (Figure 2) in Group A and Group $B$ was on a continuous rise over the period of confirmed pregnancy. This increase was statistically significant at days 7, 14, 21 and 28 of pregnancy in Group B compared to Group A $(\mathrm{p}<0.05)$. These findings correlated with those of Rommers et al ${ }^{[17]}$ who reported bigger litter size in rabbits with higher body weights (i.e., fed ad libitum) at first insemination.

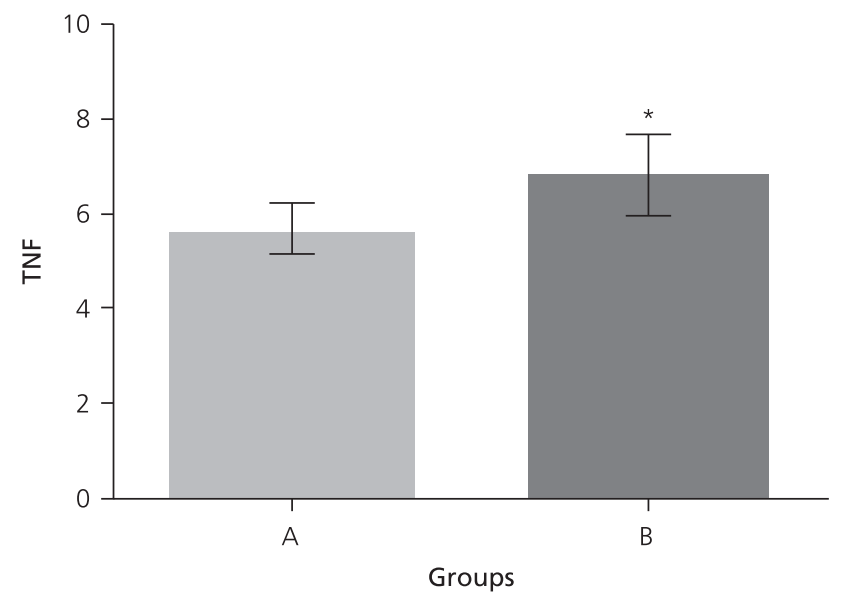

Figure 3. Total number of fetuses (TFN) in Group A and Group B. * $p<0.05$.
Table 2

Caesarean section data in Group A and Group B

\begin{tabular}{lcc}
\hline Parameters & Group A & Group B \\
\hline Number of examined pups & 28 & 34 \\
Total number of implantations & $6 \pm 0.45$ & $8.2 \pm 0.58^{*}$ \\
Number of corpora lutea & $8.2 \pm 1.64$ & $9.6 \pm 1.8$ \\
\hline Fetal deaths & & \\
Resorption/Dead fetuses & $2 / 0$ & $8 / 0$ \\
Total resorption number & $0.4 \pm 0.25$ & $1.4 \pm 0.25^{*}$ \\
\hline Live fetuses & & $18 / 16$ \\
Male/female & $14 / 12$ & 0.53 \\
Sex ratio (o'/ $+\sigma^{7}$ ) & 0.54 & None \\
\hline External abnormalities & None &
\end{tabular}

${ }^{*} p<0.05$. Sex ratio $\left(\sigma^{\gamma /} / q+\sigma^{7}\right)=($ number of live male fetuses/number of live fetuses $) \times 100$.

\section{Reproductive data}

The reproductive data for Group A and Group B in Table 1 revealed that a conception rate (CR) of $100 \%$ was observed in Group A compared to 80\% CR in Group B. This may be due to the doe irresponsiveness to the ovulatory hormonal treatment of (HCG) injection or the inability of the sperm to fertilize the vova. This was in agreement with the findings of Tawfeek and ElGaafary ${ }^{[18]}$ who reported that natural mating yielded significant litter size at birth and at weaning compared to artificial insemination (AI) using HCG treatment $(\mathrm{p}<0.05)$. Oke and Iheanacho ${ }^{[19]]}$ reported that natural mating in rabbits produced a significantly higher conception rate of $79.9 \%$ compared to $56.4 \%$ in rabbits undergoing AI, in contrast with the findings of Khalifa ${ }^{[20]}$ who reported an insignificantly higher conception rate in does that

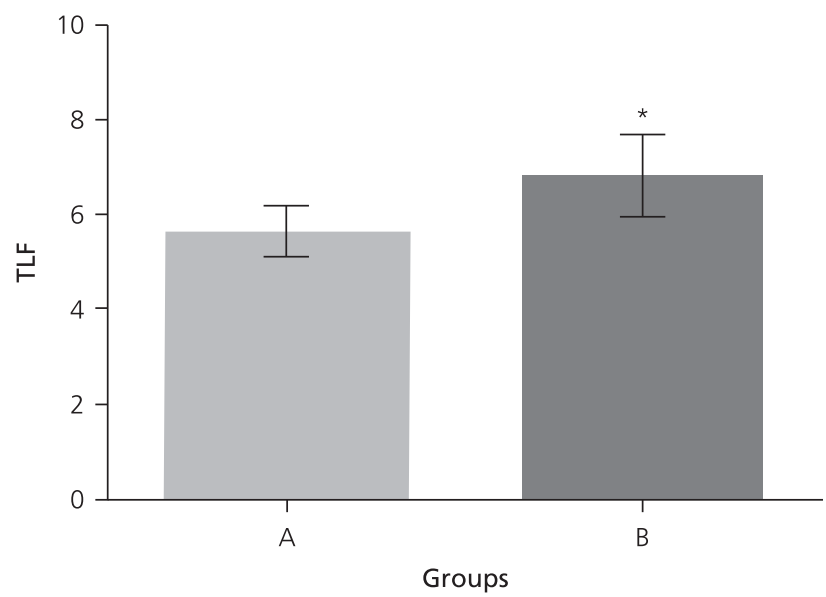

Figure 4. Total number of live fetuses (TLF) in Group A and B. * $p<0.05$. 
mated naturally. Sexual receptivity at insemination has been attributed to increase the number of live foetuses in rabbits after AI, associating it to a better fertility due to high numbers of pre-ovulatory follicles found in the ovaries and higher plasma oestrogen concentrations. ${ }^{[21]}$ The connection between sexual receptivity and ovulation is limiting gestational failures which is high in non-receptive does. Therefore, sexual receptivity of does at insemination is associated with high prolificacy at birth. This result may be due to higher ovulation intensity, fertilization rate, and embryo survival in receptive does. ${ }^{[22]}$

Abortion was observed in one doe on day 21 of gestation for Group B, while none occurred in Group A. This correlated with the findings of Hong et al ${ }^{[23]}$ and Ujhazy et al. ${ }^{[24]}$ who observed death, abortion and premature birth in some dams.

Statistical analyses on the total fetal numbers and number of live foetuses in Figures $\mathbf{3}$ and $\mathbf{4}$ showed a significant increase $(\mathrm{p}<0.05)$ for Group B compared to Group A. These findings contradicted with those of Bonanno and Costanzo ${ }^{[25]}$ and Mach et al. ${ }^{[26]}$ who reported a significantly higher litter size at birth $(\mathrm{p}<0.01)$. The reason might be dependent on quantitative features such as the number of spermatozoa in the dose via sperm concentration. This stresses the importance of selecting the ejaculates according to mass motility prior to insemination, with regard to fertility. Rapt attention must also be paid to the characteristics of the insemination dose, and particularly the number of spermatozoa per dose which influences reproductive performance. This result corroborated with the findings of Bencheikh ${ }^{[27]}$ who observed relationships between the number of spermatozoa, motility, $\mathrm{pH}$ and percentage of motile spermatozoa on the one hand, and fertility and litter size on the other hand. Bonanno et al. ${ }^{[28]}$ attributed increase in the number of live foetuses to the efficient hormonal stimulation with gonadotropin which aided follicular growth, thereby increasing fertilizing power of the sperm at the site fertilization.

\section{Caesarean section data of does}

The sex ratio $(M / F)$ showed no significant increase ( $p>0.05)$ for Group B compared to Group A bringing to the fore that more males and female rabbits were recorded in Group B compared to the Group A (Figure 8). This correlated with the findings of Hong et al. ${ }^{[23]}$ who observed no statistically significant difference when comparing the parameters like sex ratio, litter size and implantation number after developing the sperm preparation method for $\mathrm{AI}$ in the rabbit. In rabbit does, ovulation occurs 10-12 hours after copulation. This time difference from copulation to ovulation has become a pre-

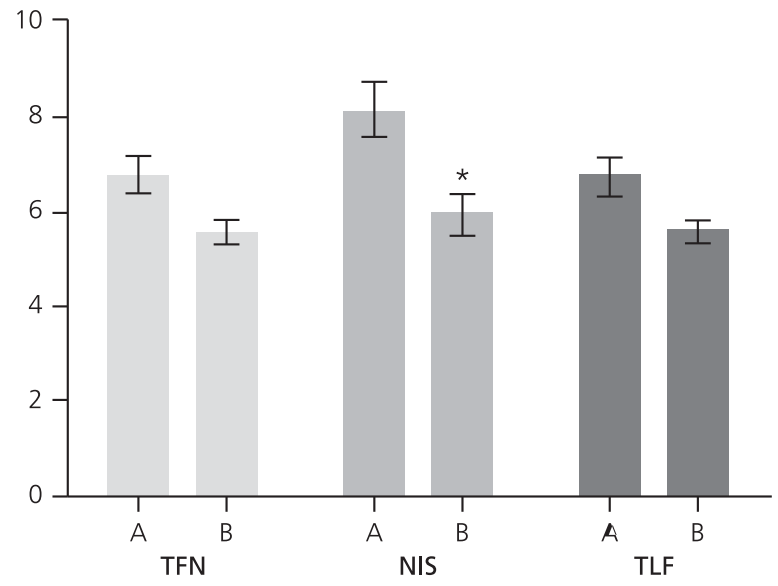

Figure 5. Total number of foetuses (TFN), implantations (NIS) and live foetuses (TLF) in Group A and Group B. * $p<0.05$.

conceptional mechanism influencing sex ratio in rabbits. ${ }^{[12]}$

The probability for a Y-bearing sperm to be fertilized by an oocyte varies as environmental and hormonal changes in the oviduct could come into play between the first and last egg in polytocous species like hares and rabbits resulting to an asynchronous ovulation according to the hormonal hypothesis of James. ${ }^{[29]}$ Early and late conceptions could determine the probability of producing more rabbit bucks within each litter. This correlated with the results of Vega et al. ${ }^{[30]}$ study who reported that late inseminated does (AI: 4-6 hours before ovulation) produced a higher proportion of male kits (59\%), which supports the hypothesis that insemination close to ovulation may favor fertilization by the earlier reacting Y-bearing sperm.

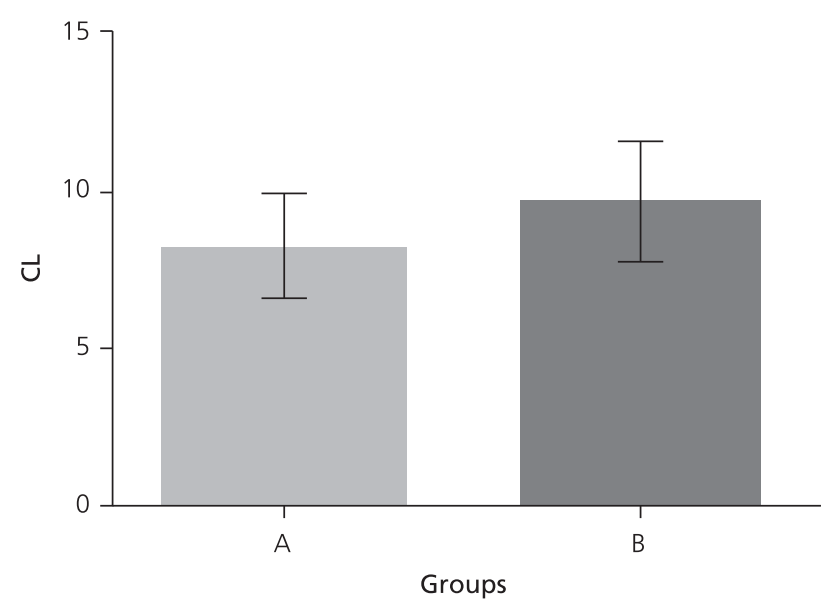

Figure 6. Number of corpora lutea $(\mathrm{CL})$ in Group A and Group B. 
Statistical analyses on the total number of resorption/prenatal losses in Figure 7 showed a significant increase $(\mathrm{p}<0.05)$ in Group B compared to Group A. These findings correlated with those of Hong et al. ${ }^{[23]}$ and Hafe ${ }^{[31,32]}$ who reported a significant increase in resorption/dead fetuses in contrast with the reports by Wolterbeek and Waalkens-Berendsen ${ }^{[33]}$ that observed no statistical difference in early and late resorptions between both groups. This result highlights some of the disadvantages encountered during the process of AI pertaining to prenatal losses. Embryonic resorption is nowadays defined as prenatal death followed by subsequent degeneration and complete resorption of the conceptus. It usually occurs at the zygotic/embryonic stage of pregnancy and thus can be clearly differentiated from late pregnancy failure like abortion. ${ }^{[3]}$ Embryonic resorption is generally associated with lack of clinical signs that precede the death of the conceptus. It is therefore also referred to as spontaneous embryonic resorption. Often a pathologic agent is not found, implying that non-infectious factors like hormonalimmunological factors, nutritional imbalances and metabolic diseases may be responsible for the death of the embryo. ${ }^{[35]}$ In rabbits, embryonic fluid resorption was observed after administration of aglepristone. ${ }^{[36]}$ Studies have shown that low serum levels of $17 \beta$-estradiol precedes embryonic resorption in rabbits which indicates a signalling failure in the embryo. ${ }^{[37]}$

Placenta weight $(\mathrm{g})$ showed no significant increase ( $>0.05)$ for Group B compared to Group A (Figure 8). This corroborated with the findings of Wolterbeek and Waalkens-Berendsen ${ }^{[33]}$ who reported no significant difference in placental weights observed between the control group and the $\mathrm{AI}$ animals fed trehalose in the diet.

Uterine gravid weight $(\mathrm{g})$ showed no significant increase $(\mathrm{p}>0.05)$ in Group B compared to Group A (Figure 9). This correlated with the findings of Wolterbeek and Waalkens-Berendsen ${ }^{[33]}$ who observed no remarkable difference for gravid and empty uterus weight, ovary weight, carcass weight and net weight change (i.e. body weight gain from day 0 to day 29 of gestation minus gravid uterine weight), observed between the control and AI groups fed with trehalose.

The number of implantations (NIS) showed a significant reduction $(\mathrm{p}<0.05)$ in Group A compared to Group B (Figure 5). This contradicts reports by Wolterbeek and Waalkens-Berendsen ${ }^{[33]}$ and Hong et al. ${ }^{[23]}$ who observed no statistical difference in the number of implantations. Reports by Williams et al. ${ }^{[3]}$ who inseminated sperm numbers ranging from $0.25 \times 10^{6}$ to $>200 \times$ $10^{6}$ motile sperm reported that the number of implantation sites on day 13 of pregnancy was reduced when

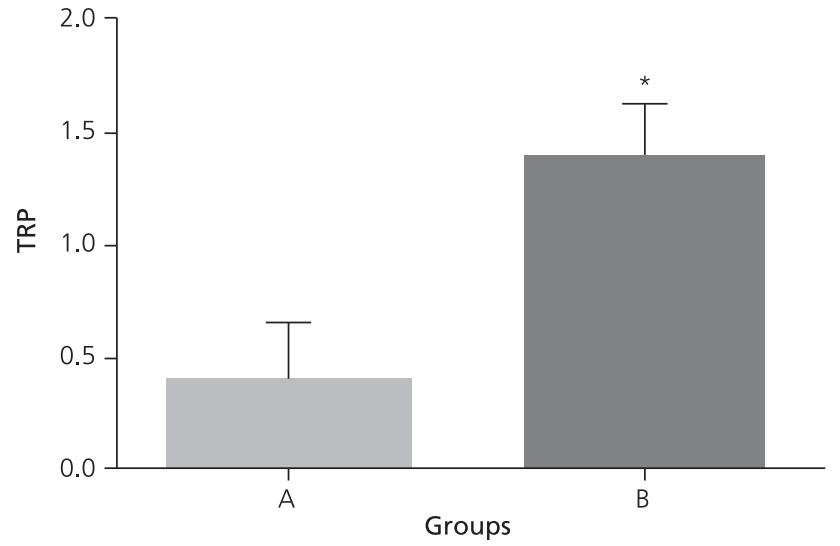

Figure 7. Total number of resorption (TRP) in Group A and Group B. ${ }^{*} p<0.05$

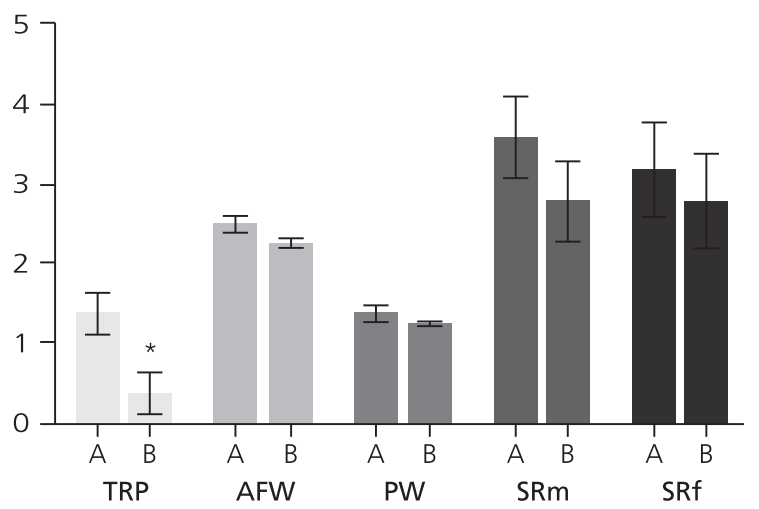

Figure 8. Total number of resorption sites (TRP), average fetal weight (AFW), placenta weight (PW), sex ratio male (SRm) and sex ratio female (SRf) in Group A and Group B. ${ }^{*} \mathrm{p}<0.05$

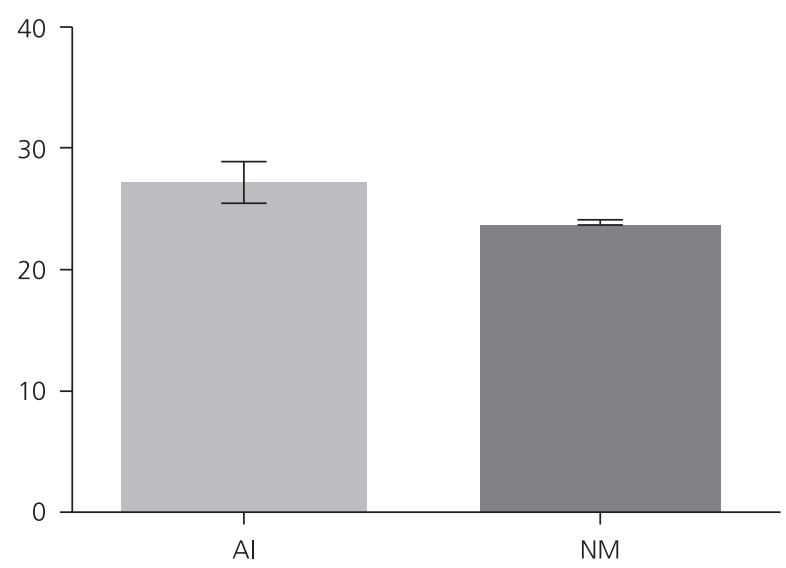

Figure 9. Uterine gravid weight (g) in Group A (Al) and Group B (NM: natural mating). ${ }^{*} \mathrm{p}<0.05$.

fewer than $1 \times 10^{6}$ motile sperm were inseminated. This shows that insemination dose may play a major role in determining the maximal fertility. The significant reduc- 
tion in the number of implantation reported might be due to the action of phagocytic enzymes within the female reproductive tract, vagina expulsion through the vagina, enzyme dissolution or migration into the abdominal cavity. Low recovery rate can be attributed to sperm phagocytosis and dissolution within the vagina. More so, comparing the inseminate number, very few spermatozoa are transported through the cervix, it is unlikely the deficit could be as a result of the phagocytic action or mass migration from the oviduct and uterus into the abdominal cavity. ${ }^{[39]}$ The insignificant increase reported in Group B that were inseminated may be due to high capacitation and the acrosome reaction taken place within in rabbits resulting in high numbers of fertilizable spermatozoa which further elucidated better and increased implantation.

Molecular mechanisms linked to this include an increase in membrane permeability to calcium, modification of the membrane structure, activation of the enzyme adenyl cyclase and conversion of the protein proacrosin to acrosin. This correlated with the study of Nadir et al. ${ }^{[40]}$ who reported that the higher the dose, the greater the competition between spermatozoa at the site of fertilization, increasing the probability of an ovum being fertilized by normal sperm, ensuring both a good fertilization rate and normal subsequent embryonic development. This hypothesis could explain why the number of spermatozoa acts both upon fertilization rate and litter size.

The particulate fraction found in the seminal plasma of mammalian species plays an important role in reproductive physiology as shown by recent studies. These particles vary from one species to the other, because their secretion, function and biochemical composition arise from different accessory glands of the male reproductive system. These particles also modulate the process of capacitation, acrosomal reaction of spermatozoa, sperm kinetics and transit as well as immune-response in the female reproductive tract. $^{[41]}$

The average fetal weight showed no significant increase $(\mathrm{p}>0.05)$ in Group B compared to Group A (Figure 8) correlating the findings of Wolterbeek and Waalkens-Berendsen ${ }^{[33]}$ who observed similar non-significant differences in the mean fetal body weight between the control and treatment groups.

No external abnormalities were recorded in both Groups A and B as shown in Table 2 at caesarean section, similar to the findings of Wolterbeek and WaalkensBerendsen ${ }^{[3]}$ who reported that external observations of the foetuses and placentas at caesarean section did not reveal any remarkable findings which could be related to treatment of trehalose after AI.
Histological studies of the ovaries shed more light on the numbers of corpora lutea as shown in Figure 6. No significant increase $(p>0.05)$ was observed in Group B compared to Group A corroborating the findings of Boiti et al. ${ }^{[42]}$ who observed that almost $20 \%$ of the rabbits have, at insemination, high plasma progesterone concentrations, associating it with an increased number of corpora lutea. Theau Clément ${ }^{[1]}$ reported two generations of corpora lutea (from 11 to 33) 24 hours after insemination and it corresponded to the injection of the hormonal treatment.

The production of luteal progesterone from the corpus luteum helps maintain pregnancy, stating the need for the embryo to send out signals to prolong its life during the period of pregnancy. ${ }^{[43]}$ Placental luteotropin in rabbits has been implicated as the embryonic signal for maintaining luteal hormone production during pregnancy. ${ }^{[44]}$ Luteotropin sustains luteal function by follicular production of estradiol, the major luteotropic hormone in the rabbit. ${ }^{[45]}$ Care should be taken during treatment with hormonal treatment during AI, because continuous use over a long period can reduce its efficacy. This phenomenon is correlated to the appearance of antibodies in the plasma of certain treated female animals. Cervantes ${ }^{[46]}$ reported that the maintenance of the corpus luteum function is dependent on the presence of the conceptus and estradiol further, stating that the primary trigger for ovulation induction in rabbits has not been well understood, but a major role is played by the pituitary gland in ovulation occurrence.

\section{Conclusion}

$\mathrm{AI}$ in rabbits is well established in many researches, breeding facilities, farms and laboratories. The advantages of AI compared to natural mating in rabbits are numerous that they outweigh their disadvantages. In spite of these advantages, there are several drawbacks like immature spermatozoa, delayed fertilization and failure, fetal abnormalities and prenatal losses while conducting AI. The results of our study show that AI with sperm collected from the cauda epididymis of rabbits is viable and a useful tool in rabbit breeding, embryo-fetal developmental studies etc. This study also suggests that there may be clear advantages in the use of rabbits for AI because of its embryofetal developmental attributes which are similar to the human. This may make the rabbit a particularly suitable model for embryo-fetal developmental studies on offspring's and adult health, as significant insights into various aspects of reproduction will be gained by its application. 


\section{References}

1. Theau Clément M. Advances in biostimulation methods applied to rabbit reproduction. World Rabbit Science 2000;8:61-79.

2. Ombelet W, Van Robays J. Artificial insemination history: hurdles and milestones. Facts Views Vis Obgyn 2015;7:137-43.

3. Carluccio A, Robbe D, De Amicis I, Contri A, Tosi U, Russo F, Paoletti M. Artificial insemination in rabbits: laboratory and field trial with three different semen extenders. World Rabbit Science 2004;12:65-79.

4. Orji BI, Igboeli G, Nwakalor LN. Semen characteristics of Muturu bulls - Bos brachyceros. Theriogenology 1984;22:197-203.

5. Barje PP, Osinowo OA, Dim NI. Effects of diluents, storage and depth of insemination on the fertility of chilled ram spermatozoa. Nigerian Journal of Animal Production 1994;21:42-6.

6. Dede TI, Steinbach J. Artificial insemination of pigs in Nigeria: a preliminary report. Nigerian Journal of Animal Production 1977; $4: 101-8$

7. Cherms FL. Variations in semen quality and relationship of semen quality to fertility in turkeys. Poult Sci 1968;47:746-54.

8. Rose ID. Semen characteristics, fertility and hatchability in some breeds of cocks. MSc Thesis, Abubakar Tafawa Balewa University, Bauchi, Nigeria, 2000. p. 24-7.

9. Quintela LA, Peña AI, Vega MD, Gullón J, Prieto MC, Barrio M, Becerra JJ, Maseda F, Herrdón PG. Ovulation induction in rabbit does submitted to artificial insemination by adding buserelin to the seminal dose. Reprod Nutr Dev 2004;44:79-88.

10. Morrell JM. Artificial insemination in rabbits. Br Vet J 1995;151: 477-88.

11. Walton A. The relation between "density" of sperm-suspension and fertility: as determined by artificial insemination of rabbits. Proc Roy Soc Lond B 1927;101-303.

12. Boussit D. Reproduction et insémination artificielle en cuniculture. Lempdes (France): Association Fran.aise de Cuniculture, INRA; 1989. p. 234.

13. Mroueh A, Mastroianni L Jr. Insemination via the intraperitoneal route in rabbits. Fert Steril 1966;17:76-82.

14. Kim JC, Chung MK, Han SS. An artificial insemination technique for obtaining pregnant does in rabbit teratogenicity studies. Korean Journal of Laboratory Animal Science 1996;12:141-6.

15. Wise LD, Beck SL, Beltrame D, Beyer BK, Chahoud I, Clark RL, Clark R, Druga AM, Feuston MH, Guittin P, Henwood SM, Kimmel CA, Lindstrom P, Palmer AK, Petrere JA, Solomon HM, Yasuda M, York RG. Terminology of developmental abnormalities in common laboratory mammals (version 1). Teratology 1997;55: 249-92.

16. Drury RAB, Wallington EA. Preparation and fixation of tissues. In: Drury RAB, Wallington EA, editors. Carleton's histological technique. 5th ed. Oxford: Oxford University Press; 1980. pp. 41-54.

17. Rommers JM, Meijerhoft R, Noordhuizen JP, Kemp B. Relationships between body weight at first mating and subsequent body development, feed intake, and reproductive performance of rabbit does. J Anim Sci 2002;80:2036-42.

18. Tawfeek MI, El-Gaafary MN. Evaluation of A.I. technique as compared to natural mating in association with some productive and reproductive traits in rabbits. Egyptian Journal of Rabbit Science 1991;1:13-20.

19. Oke UK, Iheanacho VC. Effect of breed and breeding system on reproductive performance of rabbits in a humid tropical environment. Tropical and Subtropical Agroecosystems 2011;14:369-73.
20. Khalifa RM. Mating frequency and artificial insemination in rabbits using vasectomized buck. World Rabbit Science 1994;2:1-5.

21. Kermabon AY, Belair L, Theau-Clément M, Salesse R, Djiane J. Effect of anoestrus and bromocryptine treatment on the expression of prolactin and LH receptors in the rabbit ovary during lactation. J Reprod Fertil 1994;102:131-8.

22. Rebollar PG, Ubilla E, Alvariño JMR, Illera JC, Silvan G. Effect of the level of sexual receptivity on plasma estradiol and the ovulatory response during the postpartum period in the rabbit. [Article in Spanish] Rev Esp Fisiol 1992;48:13-7.

23. Hong JS, Yu WJ, Kim YS, Cho JS, Park MK, Cho SM, Yi H, Cho HJ, Shin HC. Development of a sperm preparation method for artificial insemination in rabbits. Journal of Animal and Veterinary Advances 2012;11:712-8.

24. Ujházy E, Sadlonová I, Dubovick $M$, Mach $M$, Múcková $M$, Flaskárová E. Teratological study of the herbicide 4-chloro-2methylphenoxyacetic acid in rabbits. J Appl Toxicol 2006;26:368-73.

25. Bonanno A, Costanzo D. The effect of physiological and climatic factors on the main reproductive traits of artificially inseminated rabbits. Rivista di Coniglicoltura 1987;24:33-9.

26. Mach K, Trojan V, Nedvedova V. Fertility, growth and feed consumption in California and New Zealand White purebred and crossbred rabbits. Zivocisna Vyriba 1986;44:109-23.

27. Bencheikh N. Production de sperme et fertilité du lapin male, Oryctolagus cuniculus. Effets de la fréquence de collecte et du type génétique. [Internet] Thèse de doctorat, Ecole Nationale Supérieure Agronomique de Toulouse, France. Available from: http://prodinra. inra.fr/record/110398

28. Bonnano A, Budetta G, Alabiso M, Alicata M. Effect of PGSG and $\mathrm{GnRH}$ treatment on the ovulatory efficiency of rabbits. Acta Medica Veterinaria 1990;36:441-51.

29. James WH. Evidence that mammalian sex ratios at birth are partially controlled by parental hormone levels at the time of conception. J Endocrinol 2008;198:3-15.

30. Vega MD, Peña AI, Gullón J, Prieto C, Barrio M, Becerra JJ, Herradón PG, Quintela LA. Sex ratio in rabbits following modified artificial insemination. Anim Reprod Sci 2008;103:385-91.

31. Hafez ES. Growth and survival of blastocysts in the domestic rabbit. II. Quantitative effects of exogenous progesterone following ovariectomy. J Reprod Fertil 1964;7:241-9.

32. Hafez ES. Maternal effects on implantation and related phenomena in the rabbit. Experientia 1965;21:234-7.

33. Wolterbeek APM, Waalkens-Berendsen DH. Oral embryotoxicity/ teratogenicity study with trehalose in New Zealand White rabbits. TNO Nutrition and Food Research Institute. TNO Peport 1999;98: $1-25$.

34. Jubb KVF, Kennedy PC, Palmer NC. Female genital tract. In: Maxie MG, Jubb KVF, Kennedy PC, Palmer N, editors. Pathology of domestic animals. 5th ed. London: Elsevier Saunders; 2007. p. 476.

35. Sendag S, Dinc DA, Celik HA, Aydin I, Wehrend A. Sonographische Verlaufsuntersuchungen an trächtigen Hündinnen. - ein Beitrag zur Bedeutung der Fruchtresorption beim Hund. Tieraerztliche Praxis Kleintiere 2010;3:133-8.

36. Özalp GR, Temizel EM, Özocak-Batmaz E. Clinical, ultrasonography and haematology of aglepristone-inducedmid-gestation pregnancy terminations in rabbits. J S Afr Vet Assoc 2013;84:E1-5. 
37. Vicente JS, Llobat L, Viudes-de-Castro MP, Lavara R, Baselga M, Marco-Jiménez F. Gestational losses in a rabbit line selected for growth rate. Theriogenology 2012;77:81-8.

38. Williams J, Gladen BC, Schrader SM, Turner TW, Phelps JL, Chapin RE. Semen analysis and fertility assessment in rabbits: statistical power and design considerations for toxicology studies. Fundam Appl Toxicol 1990;15:651-5.

39. Morton DB, Glover TD. Sperm transport in the female rabbit: the effect of inseminate volume and sperm density. J Reprod Fertil 1974:38:139-46.

40. Nadir S, Saacke RG, Bame J, Mullins J, Degelos S. Effect of freezing semen and dosage of sperm on number of accessory sperm, fertility and embryo quality in artificially inseminated cattle. J Anim Sci 1993;71:199-204.

41. Johansson M, Bromfield JJ, Jasper MJ, Robertson SA. Semen activates the female immune response during early pregnancy in mice. Immunology 2004;112:290-300.

42. Boiti C, Canali C, Monaci M, Stradaioli G, Verini Supplizi A, Vacca C, Castellini C, Facchin E. Effect of postpartum proges- terone levels on receptivity, ovarian response, embryo quality and development in rabbits. Proceedings of the 6th World Rabbit Congress 1996;2:45-9.

43. Schroeder K, Drews B, Roellig K, Goeritz F, Hildebrandt TB. Embryonic resorption in context to intragestational corpus luteum regression: a longitudinal ultrasonographic study in the European brown hare (Lepus europaeus PALLAS, 1778). Theriogenology 2013;80:778-84.

44. Marcinkiewicz JL, Bahr JM. Identification and preliminary characterization of luteotropic activity in the rabbit placenta. Biol Reprod 1993;48:403-8.

45. Dharmarajan AM, Zanagnolo VL, Dasko LM, Zirkin BR, Ewing LL, Wallach EE. Estradiol regulation of the rabbit corpus luteum: in vivo and in vitro studies. Endocrinology 1991;128:2678-84.

46. Cervantes MP. The rabbit as an animal model for the study of ovulation-inducing factor. [Internet] Master Thesis, University of Saskatchewan, Saskatoon, SK, Canada, 2011. Available from: https://ecommons. usask.ca/handle/10388/ETD-2011-08-63

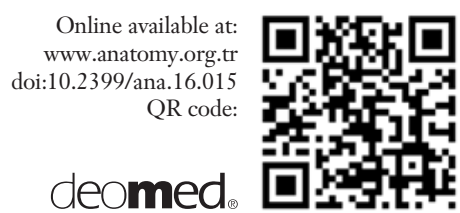

Correspondence to: Adeoye Oyetunji Oyewopo, PhD

Department of Anatomy, Faculty of Basic Medical Sciences, University of Ilorin, P.M.B. 1515, llorin, Kwara State, Nigeria Phone: +234803 3925431

e-mail:wolesake@yahoo.com.com; oyewopo.ao@unilorin.edu.ng

Conflict of interest statement: No conflicts declared.

This is an open access article distributed under the terms of the Creative Commons Attribution-NonCommercial-NoDerivs 3.0 Unported (CC BY-NCND3.0) Licence (http://creativecommons.org/licenses/by-nc-nd/3.0/) which permits unrestricted noncommercial use, distribution, and reproduction in any medium, provided the original work is properly cited. Please cite this article as: Obasi KK, Lambe E, Gbadamosi IT, Oyewopo AO. A comparative study on the embryo-fetal development in rabbits after artificial insemination. Anatomy 2016;10(2):105-113. 